\title{
The effect of domiciliary noninvasive ventilation on clinical outcomes in stable and recently hospitalized patients with COPD: a systematic review and meta-analysis
}

\author{
This article was published in the following Dove Press journal: \\ International Journal of COPD \\ 16 September 2016 \\ Number of times this article has been viewed
}

\author{
Janine Dretzke' \\ David Moore' \\ Chirag Dave ${ }^{2}$ \\ Rahul Mukherjee ${ }^{2}$ \\ Malcolm J Price' \\ Sue Bayliss' \\ Xiaoying Wu' \\ Rachel E Jordan' \\ Alice M Turner ${ }^{2,3}$ \\ 'Institute of Applied Health Research, \\ College of Medical and Dental \\ Sciences, University of Birmingham, \\ Edgbaston, ${ }^{2}$ Heart of England \\ NHS Foundation Trust, Heartlands \\ Hospital, ${ }^{3}$ Queen Elizabeth Hospital \\ Research Laboratories, University \\ of Birmingham, Edgbaston, \\ Birmingham, UK
}

Correspondence: David Moore Institute of Applied Health Research, College of Medical and Dental Sciences, University of Birmingham, Edgbaston, Birmingham BI5 2TT, UK

Tel +44 I2I 4I 4449

Email d.j.moore@bham.ac.uk
Introduction: Noninvasive ventilation (NIV) improves survival among patients with hypercapnic respiratory failure in hospital, but evidence for its use in domiciliary settings is limited. A patient's underlying risk of having an exacerbation may affect any potential benefit that can be gained from domiciliary NIV. This is the first comprehensive systematic review to stratify patients based on a proxy for exacerbation risk: patients in a stable state and those immediately post-exacerbation hospitalization.

Methods: A systematic review of nonrandomized and randomized controlled trials (RCTs) was undertaken in order to compare the relative effectiveness of different types of domiciliary NIV and usual care on hospital admissions, mortality, and health-related quality of life. Standard systematic review methods were used for identifying studies (until September 2014), quality appraisal, and synthesis. Data were presented in forest plots and pooled where appropriate using random-effects meta-analysis.

Results: Thirty-one studies were included. For stable patients, there was no evidence of a survival benefit from NIV (relative risk [RR] 0.88 [0.55, 1.43], $P^{2}=60.4 \%, \mathrm{n}=7$ RCTs), but there was a possible trend toward fewer hospitalizations (weighted mean difference -0.46 $[-1.02,0.09], I^{2}=59.2 \%, \mathrm{n}=5 \mathrm{RCTs}$ ) and improved health-related quality of life. For posthospital patients, survival benefit could not be demonstrated within the three RCTs (RR 0.89 [0.53, 1.49], $I^{2}=25.1 \%$ ), although there was evidence of benefit from four non-RCTs (RR 0.45 [0.32, $0.65], I^{2}=0 \%$ ). Effects on hospitalizations were inconsistent. Post hoc analyses suggested that NIV-related improvements in hypercapnia were associated with reduced hospital admissions across both populations. Little data were available comparing different types of NIV.

Conclusion: The effectiveness of domiciliary NIV remains uncertain; however, some patients may benefit. Further research is required to identify these patients and to explore the relevance of improvements in hypercapnia in influencing clinical outcomes. Optimum time points for commencing domiciliary NIV and equipment settings need to be established.

Keywords: noninvasive ventilation, domiciliary, COPD, hospitalization, systematic review, meta-analysis

\section{Introduction}

COPD is a chronic progressive lung disease, characterized by nonreversible airflow obstruction and intermittent exacerbations. ${ }^{1}$ Treatment for COPD is based on pharmacotherapy, pulmonary rehabilitation, and in some cases, long-term oxygen therapy. Exacerbations are a key cause of increased morbidity, mortality, and poor health status, 
and place a considerable burden on the health care system. ${ }^{2}$ Approximately $15 \%$ of COPD patients per year have exacerbations necessitating hospital admission; ${ }^{3,4}$ between $10 \%$ and $25 \%$ of patients admitted with hypercapnic respiratory failure due to COPD die in hospital. ${ }^{5}$ Reduced exacerbation frequency is therefore an important therapeutic target.

Noninvasive ventilation (NIV) is a method of providing ventilatory support via a mask and is effective in improving survival among patients with acute or acute-on-chronic hypercapnic respiratory failure in hospital. ${ }^{6,7}$ Evidence for domiciliary use of NIV in non-acute COPD patients is more limited despite a number of systematic reviews. ${ }^{8-11}$ As patients immediately posthospitalization are at greater risk of recurrence of exacerbation than those more stable, ${ }^{12}$ this difference could influence the effectiveness of NIV in preventing or reducing the impact of these events. This is the first systematic review to stratify data by these two patient groups, and it is the most comprehensive review to date, including evidence from randomized controlled trials (RCTs), non-RCTs, and RCTs comparing different NIV settings, and considering mortality, hospitalizations, and quality of life (QoL) as outcomes. Finally, this is the first systematic review to attempt an analysis, albeit exploratory, of the relationship between hypercapnia and clinical outcomes.

\section{Methods}

A protocol detailing the methodology was registered with PROSPERO (CRD42012003286). ${ }^{13,14}$ A summary of the methods is presented here. Search strategies incorporated a combination of text words and index terms relating to NIV and COPD. Bibliographic databases (MEDLINE, MEDLINE In-Process, Embase, Cochrane CENTRAL, CINAHL, and Science Citation Index Expanded (ISI)), the British Library's ZETOC and ISI Conference Proceedings Citation Index, and clinical trial registers were searched from 1980 until September 2014. No study design or language restrictions were imposed. Citation checking of included studies was undertaken, and experts in the field were consulted to identify further studies. The search strategy for MEDLINE is shown in the Supplementary material.

Studies were eligible for inclusion if they met the criteria shown in Table 1.
Primary outcomes of interest were mortality, hospitalizations, exacerbations, and QoL. Secondary outcomes included lung function and blood gases. Study selection was performed by two reviewers independently. Disagreements were resolved through discussion and/or referral to a third reviewer.

Risk of bias was assessed based on the Cochrane collaboration risk-of-bias tool (for RCTs and nonrandomized controlled studies), and additional criteria were considered for crossover trials (ie, whether there was a carry-over effect, whether only first-period data were available, whether analysis was appropriate to crossover trials, and comparability of results with those from parallel-group trials). ${ }^{15}$

Data extraction was performed by one reviewer using a standardized, piloted data extraction form, and numerical data were checked by a second reviewer. Study selection and data extraction of non-English language papers was performed by native speakers of the respective languages with guidance from the reviewers.

Studies were grouped according to average proximity of patients to their most recent exacerbation that required hospitalization. If patients had not been hospitalized within 4 weeks to 3 months at commencement of the study or were described as "stable", they were classed as the stable population. Where there was clear evidence that treatment with NIV in a study commenced after an episode of hospitalization (due to an exacerbation), these patients were classed as the posthospital population, with the assumption that on average, this population were at greater risk of a subsequent exacerbation.

Separate analyses were performed for each study design (RCT, controlled studies) and primary outcome (survival and hospitalizations). Where there was clinical and methodological homogeneity between studies reporting the same outcome and using the same outcome statistic (reported or calculable), random effects meta-analysis was undertaken in STATA (Stata Statistical Software: Release 10; StataCorp LP, College Station, TX, USA). Results for other primary outcomes were reported narratively (exacerbations and QoL). Secondary outcome data (forced expiratory volume in 1 second, forced vital capacity, partial pressure of carbon dioxide $\left[\mathrm{PaCO}_{2}\right]$, partial pressure of oxygen, 6-minute

Table I Study inclusion criteria

\begin{tabular}{lll}
\hline Study design & Patients & Intervention \\
\hline RCTs (parallel or crossover) & Adult COPD & Any form of \\
Nonrandomized controlled studies & patients & domiciliary NIV \\
Systematic reviews (for identifying further primary studies) & & form of NIV \\
\hline
\end{tabular}

Abbreviations: RCTs, randomized controlled trials; NIV, noninvasive ventilation. 
walk distance) were not pooled due to between-study heterogeneity but are presented in forest plots in order to show the overall direction of effect and uncertainty.

Exploratory post hoc analyses of study-level data were performed to determine if baseline hypercapnia could predict response to NIV, or whether change in hypercapnia correlated with any effect of NIV on mortality and hospitalizations.

Guidelines of Preferred Reporting Items for Systematic Reviews and Meta-Analyses were adhered to. ${ }^{16}$

\section{Results}

\section{Main study characteristics}

Screening of the 7,405 records identified by the searches yielded 21 RCTs (18 NIV vs usual care; three NIV vs another form of NIV) and ten nonrandomized controlled studies (five prospective, five retrospective; Figure 1). Table 2 shows the main characteristics of these studies.

All patients had Global Initiative for Chronic Obstructive Lung Disease stage III and/or IV COPD, or were described as

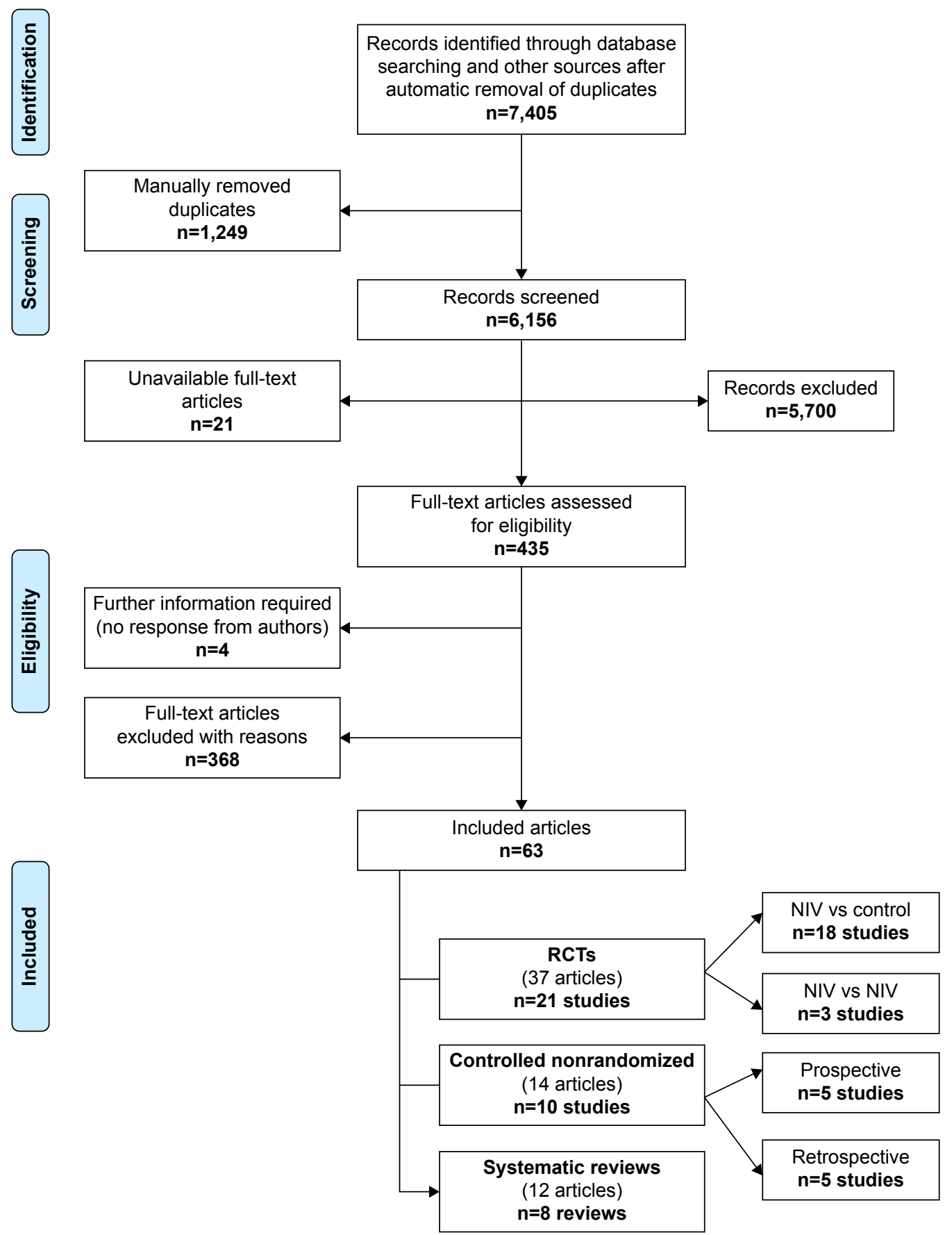

Figure I PRISMA flow diagram (study selection process).

Abbreviations: PRISMA, Preferred Reporting Items for Systematic Reviews and Meta-Analyses; RCTs, randomized controlled trials; NIV, noninvasive ventilation. 


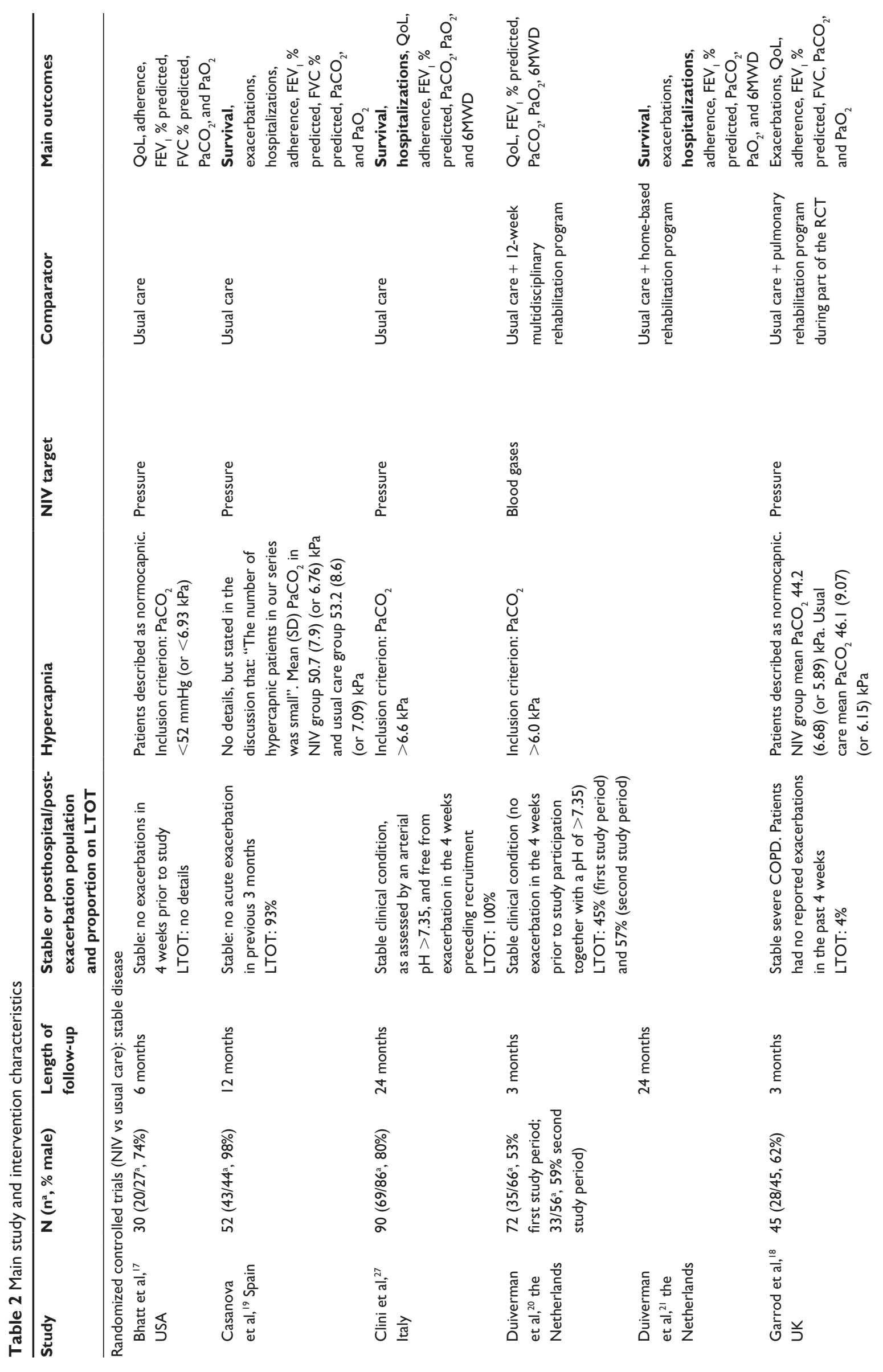




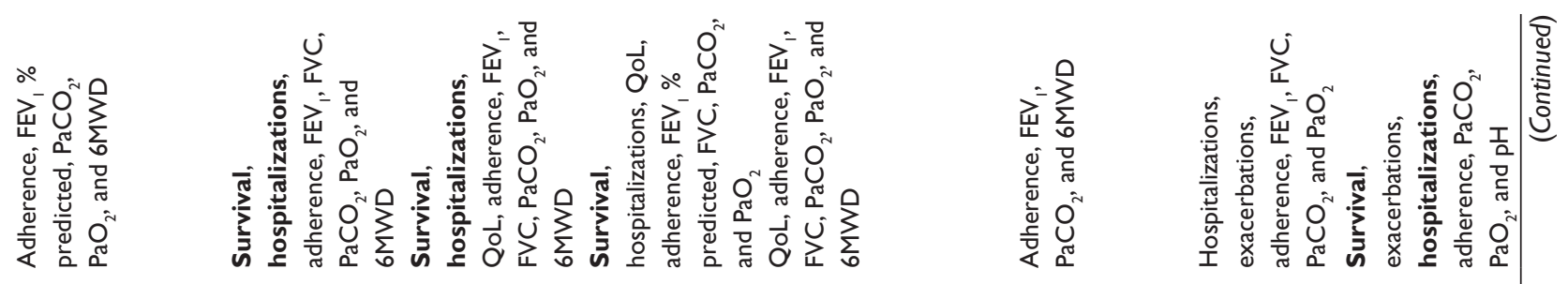

\begin{tabular}{|c|c|c|c|c|c|}
\hline 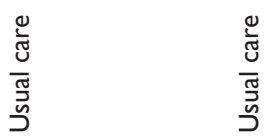 & $\frac{\text { o }}{\frac{0}{0}}$ & $\frac{\mathscr{0}}{\frac{0}{J}}$ & 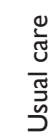 & 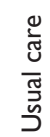 & 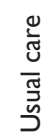 \\
\hline
\end{tabular}
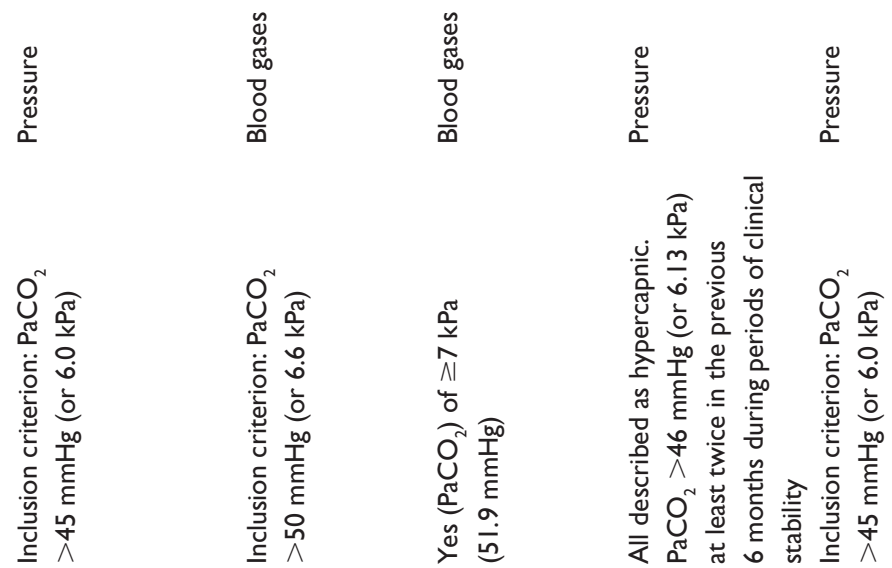

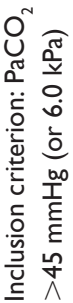

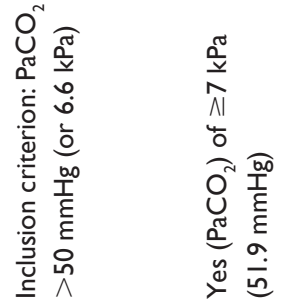

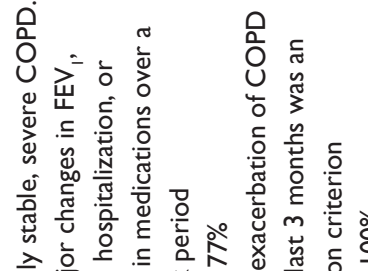

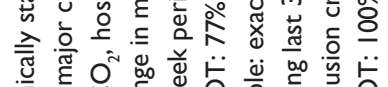

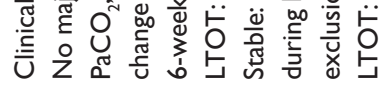

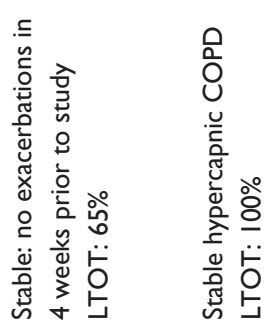

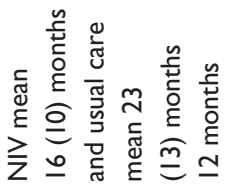

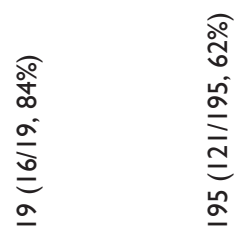

$\frac{\bar{m}}{\overline{\frac{\pi}{0}}}$

离岕

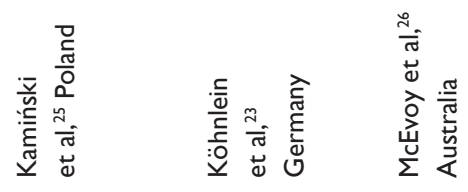

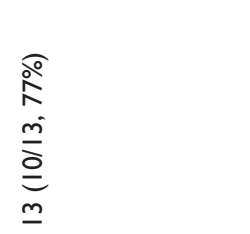

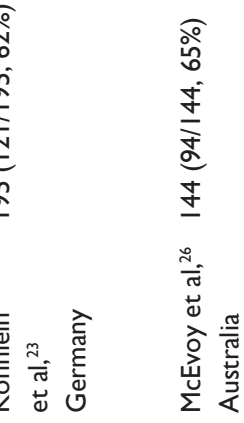

$\stackrel{0}{\overline{\bar{g}}}$

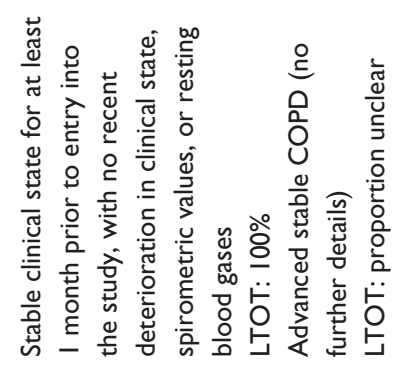

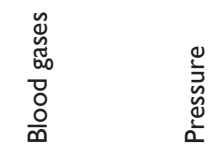

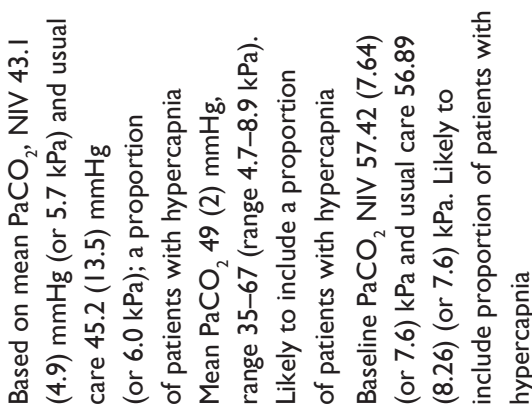

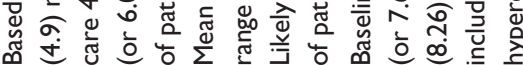

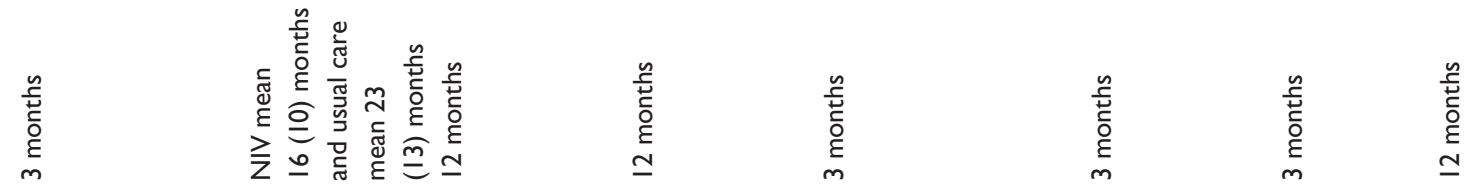

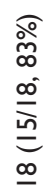

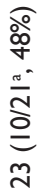

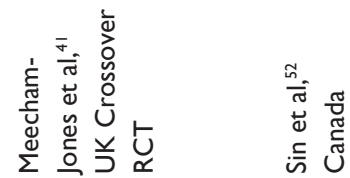

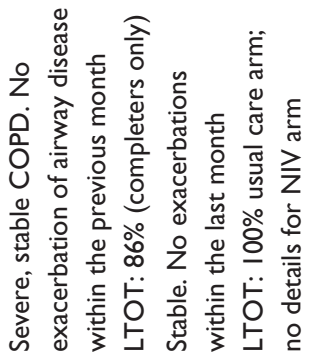

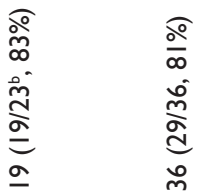

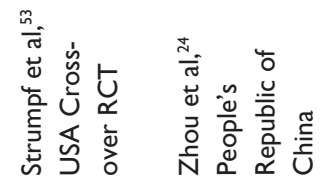




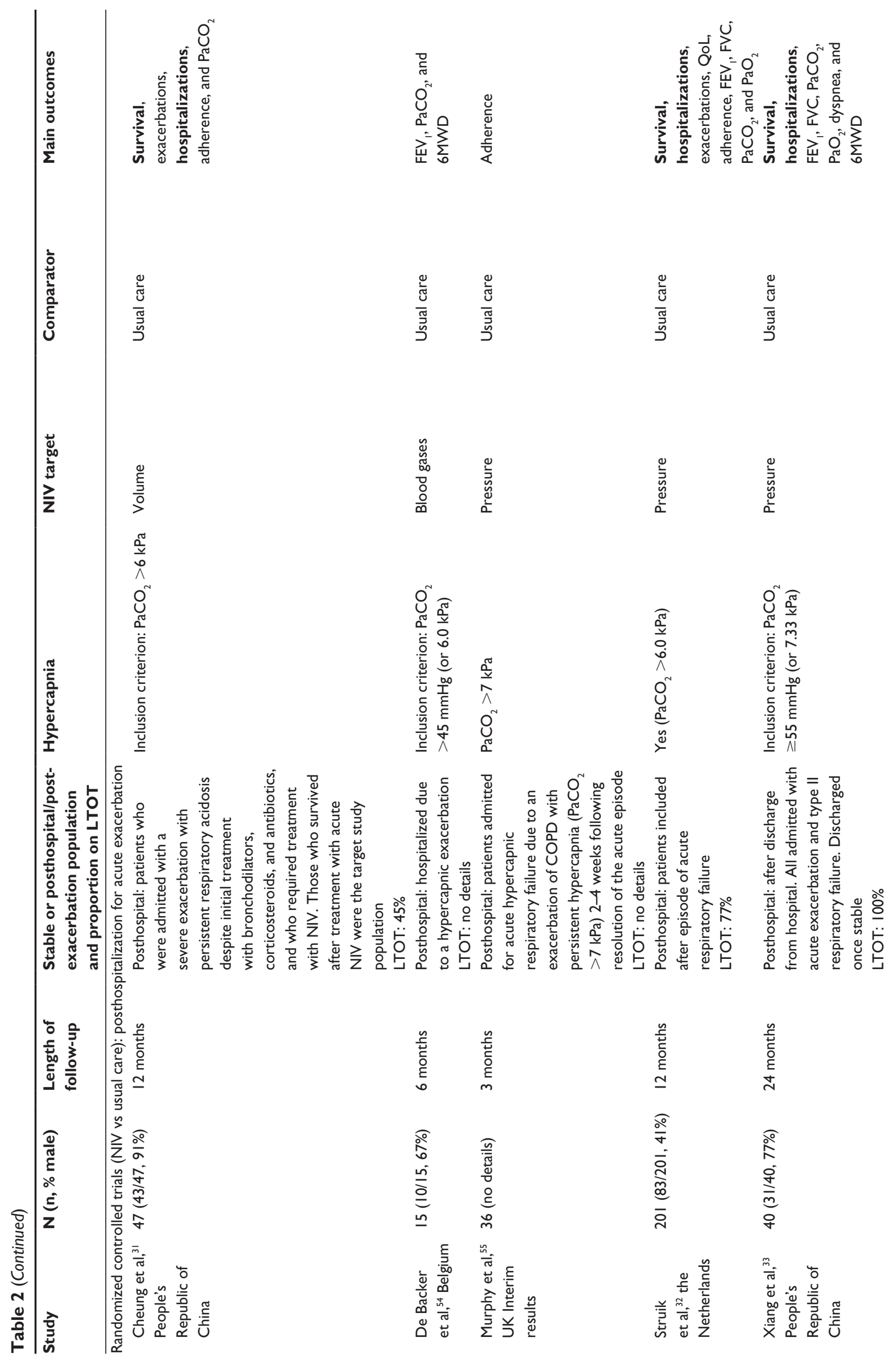



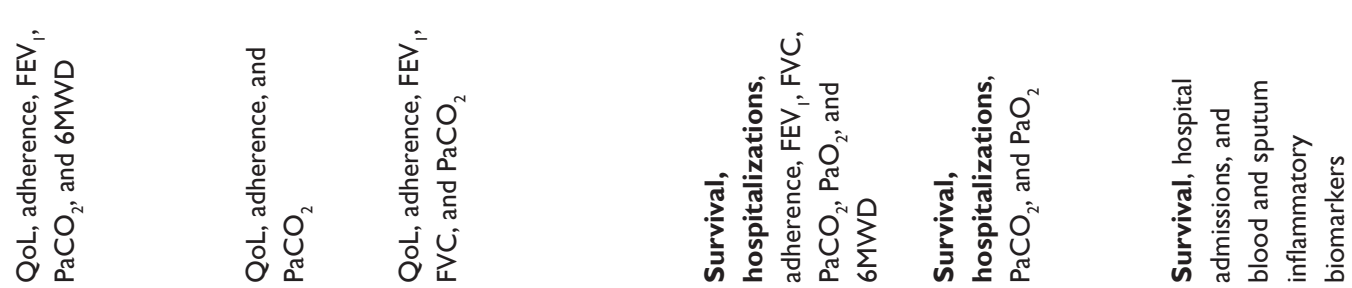

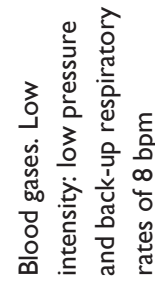
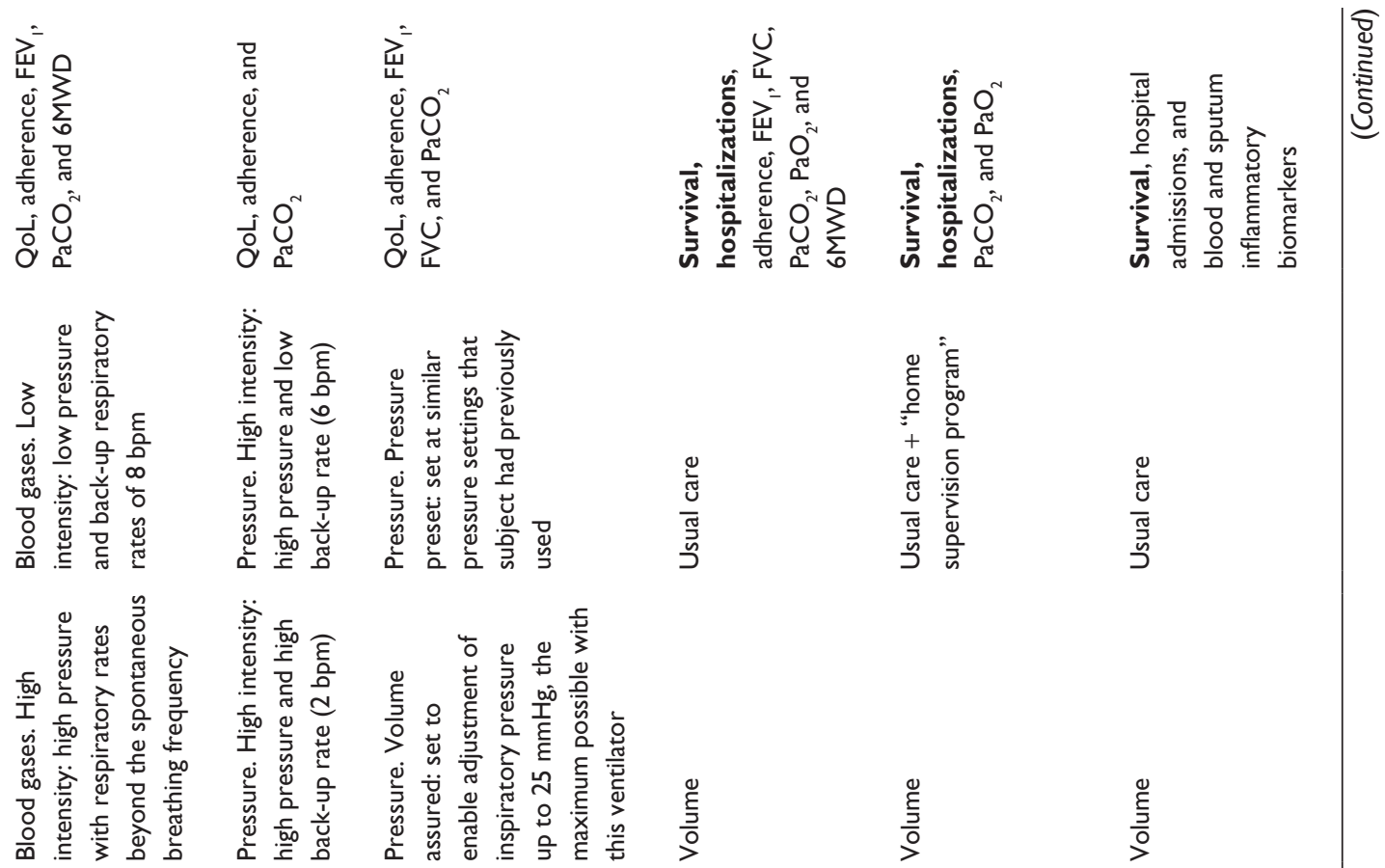

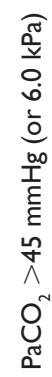

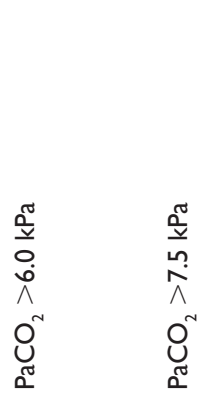

ํํำ

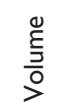

$\frac{\sqrt{\frac{5}{5}}}{\frac{0}{\frac{0}{5}}}$
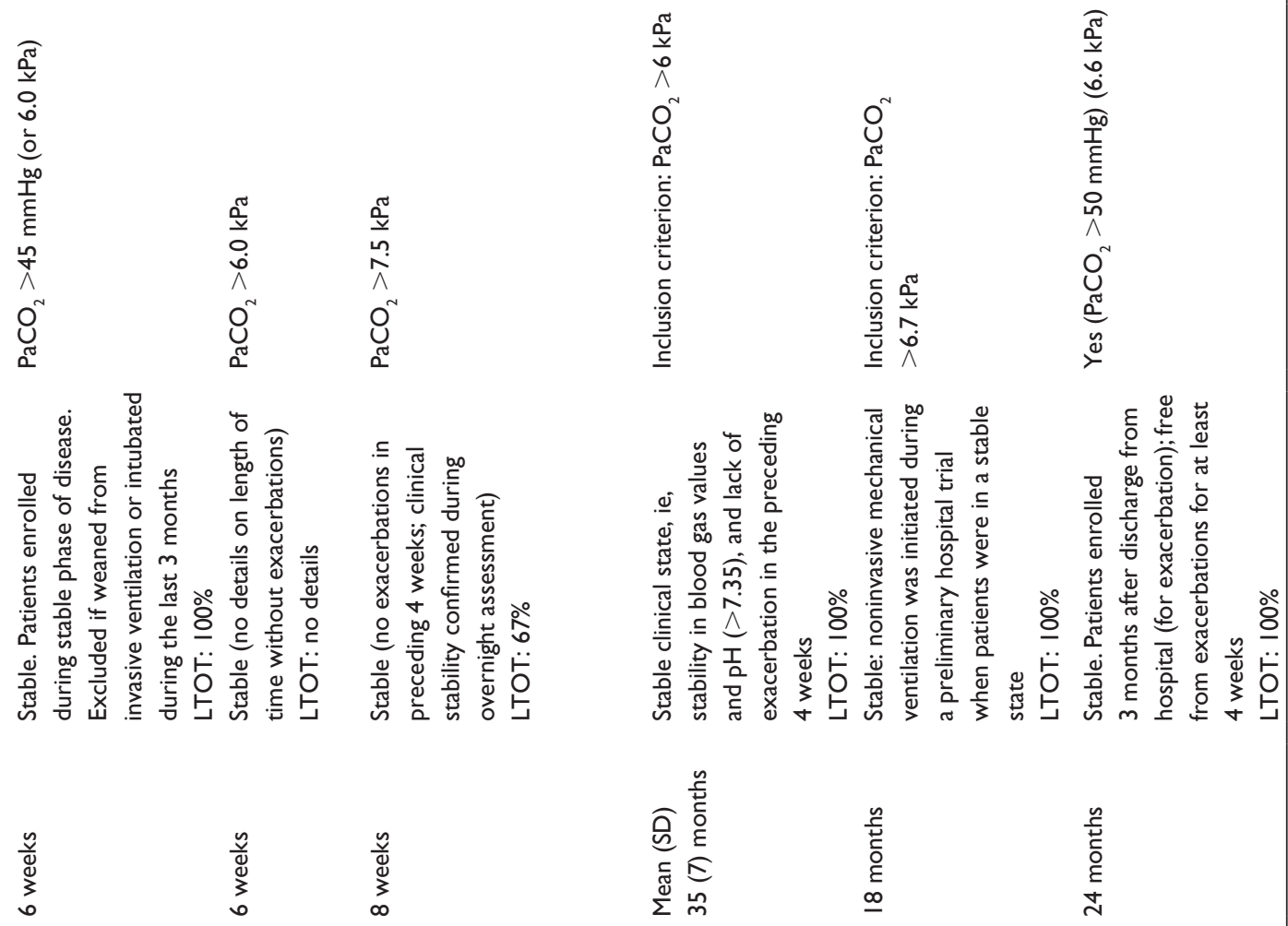

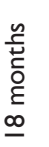
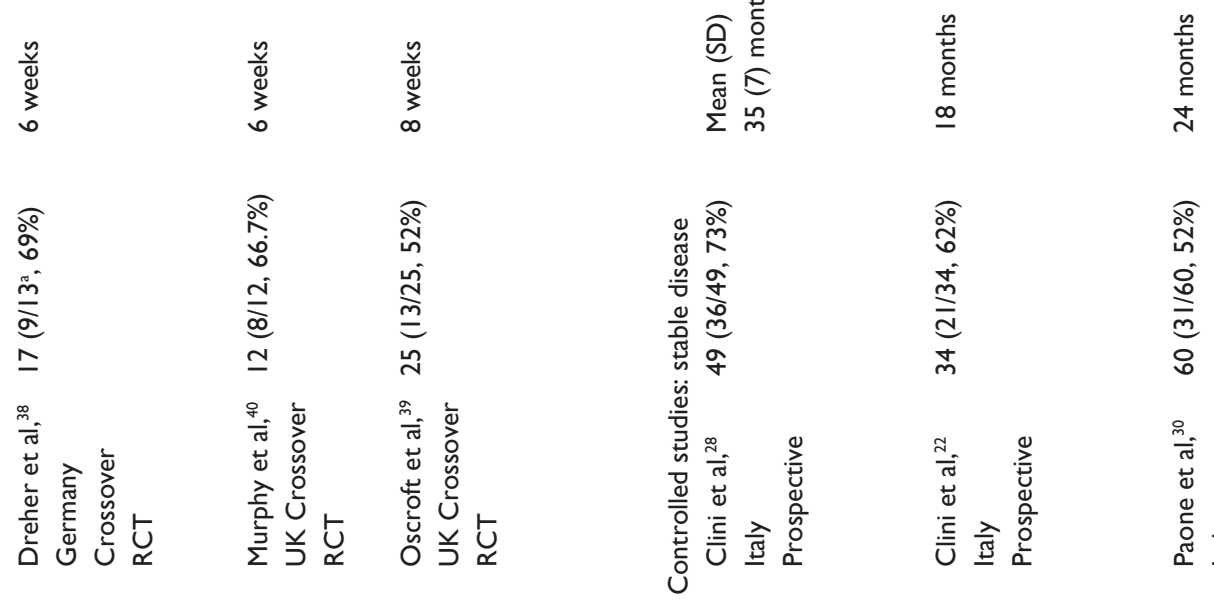

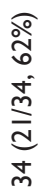

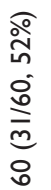
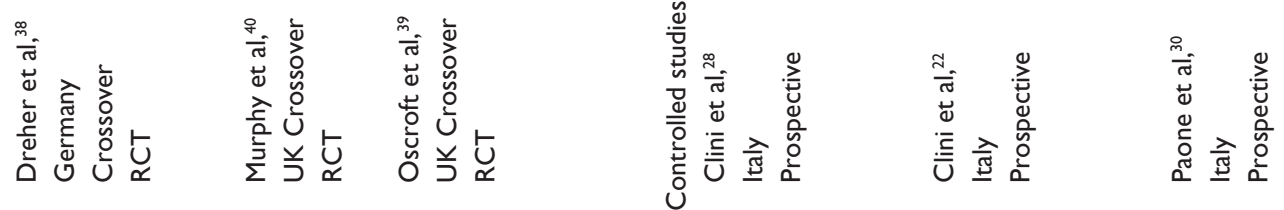


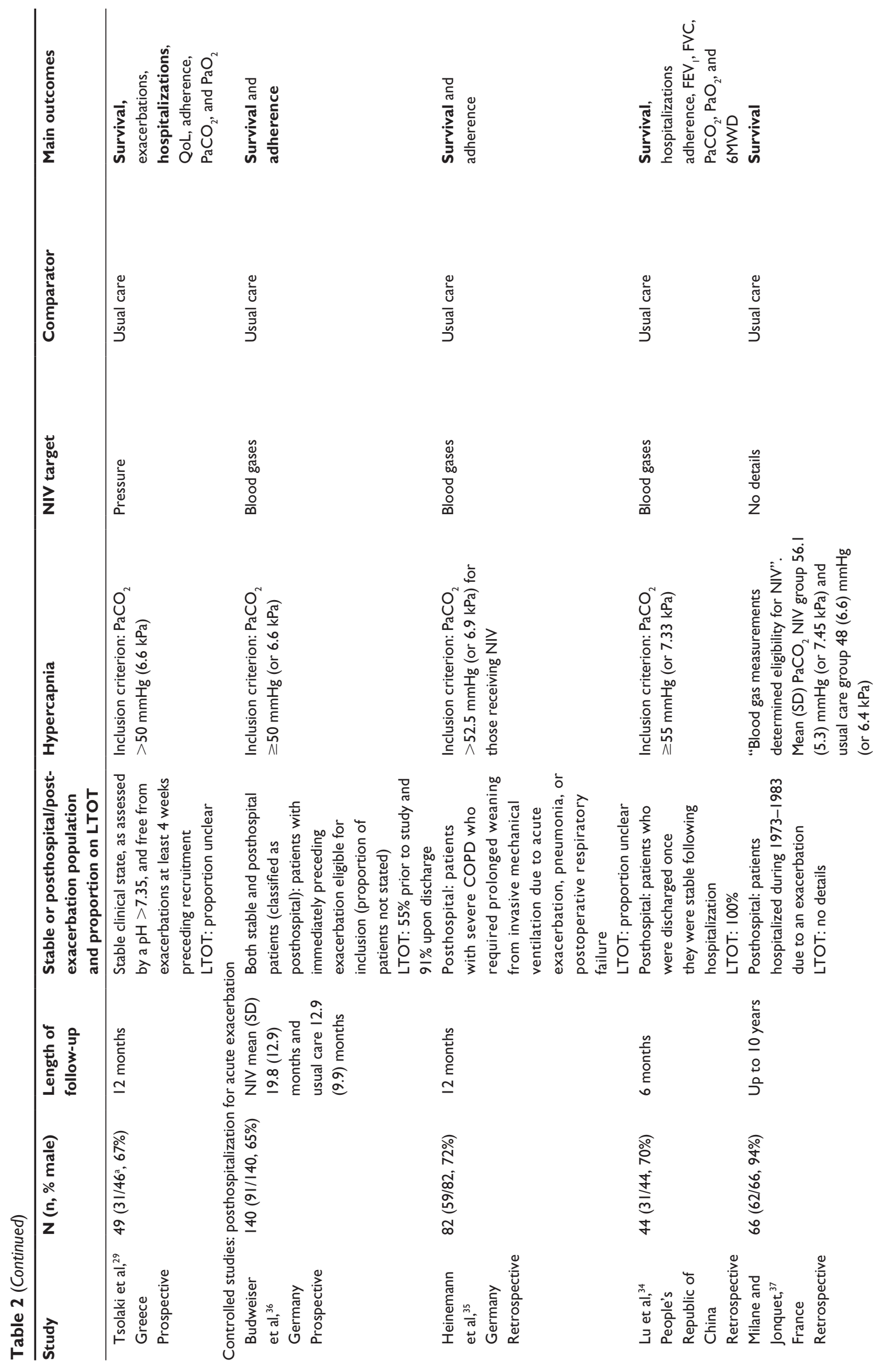


"severe" (where reported). Eighteen studies provided details on assessing patients for obstructive sleep apnea, to rule out overlap syndrome. Twenty studies were on stable populations and nine on posthospital populations, and there were no details for two. For posthospital populations, there was clear evidence in all study reports that NIV treatment commenced after hospitalization due to an exacerbation. For both populations, there was usually no information on the length of time before NIV was initiated, or previous exacerbation history. Varying proportions of patients were on long-term oxygen therapy. Most studies included hypercapnic patients, though the cut-off for classification varied. Two RCTs ${ }^{17,18}$ included normocapnic patients, while one $\mathrm{RCT}^{19}$ stated that the number of hypercapnic patients included was small.

NIV settings, therapeutic/tolerability targets (pressure, volume, or blood gases), and reporting of these varied across studies. There was some variability in usual care, with three studies considered to have more intensive approaches to usual care: a 12-week multidisciplinary rehabilitation program, followed by a long-term home-based rehabilitation program, ${ }^{20,21}$ a pulmonary rehabilitation program for part of the $\mathrm{RCT},{ }^{18}$ and a "home supervision program". ${ }^{22}$

There was a lack of reporting of some details relevant to study quality, particularly regarding loss to follow-up, handling of missing data, and blinding of outcome assessors. Only three RCTs included a "sham NIV" arm, lack of which may have led to performance bias and/or bias in patient-reported QoL. By definition, the nonrandomized studies were more prone to bias; some retrospective studies had clear evidence of baseline imbalances between NIV and comparator groups, with the consequence of this on study findings unknown.

Length of follow-up varied between 3 and 24 months (RCTs) and between 12 months and 10 years (controlled studies). The longest follow-up periods (4-10 years) were in the retrospective controlled studies.

\section{Main findings}

NIV compared with usual care only: stable population Data from seven RCTs ${ }^{19,21,23-27}$ (pooled relative risk [RR] $\left.0.88[0.55,1.43], I^{2}=60.4 \%\right)$ and four controlled studies ${ }^{22,28-30}$ (pooled RR 1.19 [0.65, 2.18], $I^{2}=0 \%$ ) suggested no significant difference between domiciliary NIV and usual care alone in terms of survival up to 24 months (Figure 2). Excluding the RCT by Casanova et al, ${ }^{19}$ which included only few patients with hypercapnia, had little effect, changing the pooled RR to $0.85(0.46,1.58)$. Data from five RCTs ${ }^{21,23-25,27}$ and three controlled studies ${ }^{22,28,29}$ (Figure 3 ) suggested a trend toward fewer hospital admissions/days in hospital with NIV, albeit 


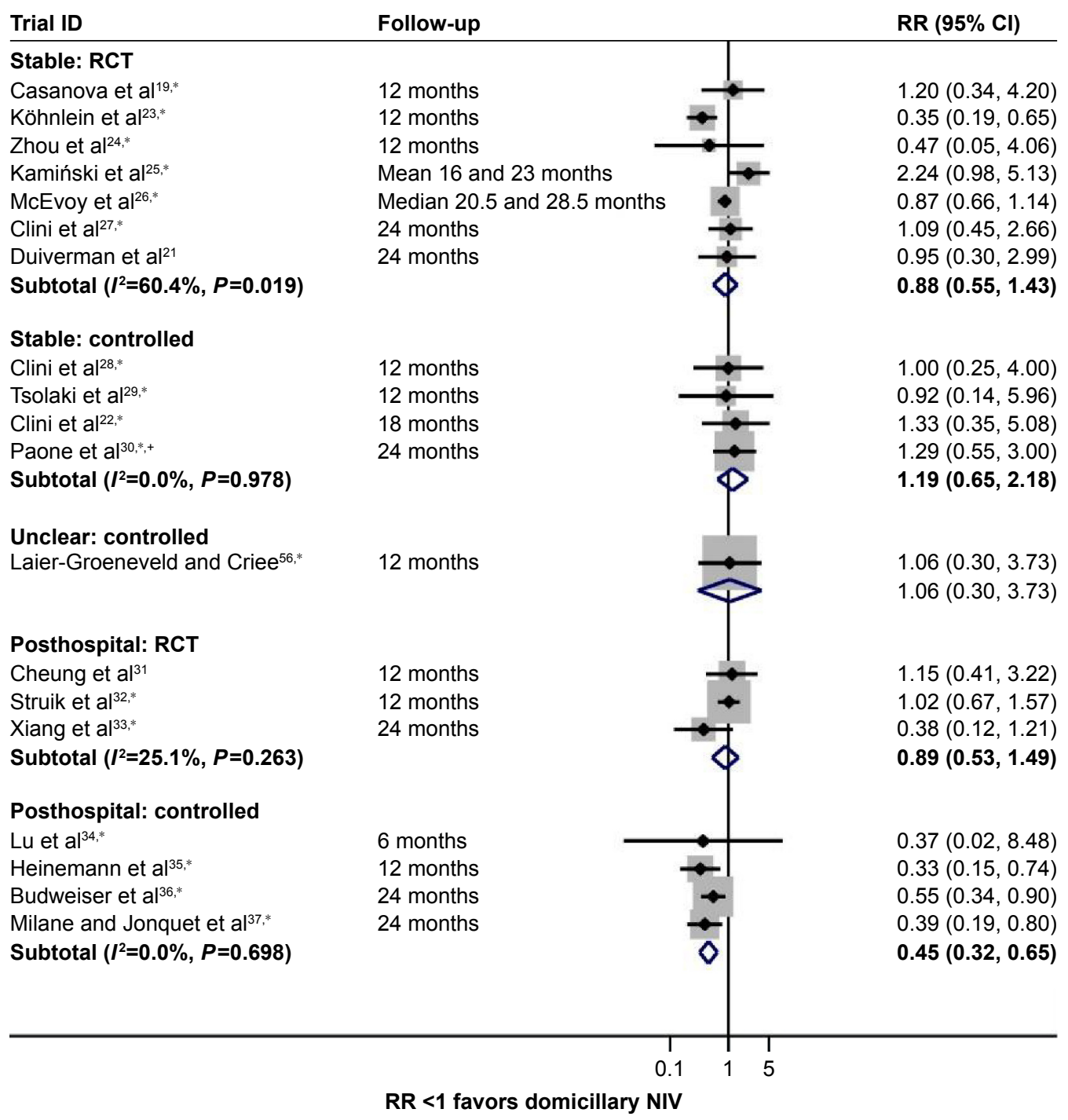

Figure 2 Mortality (relative risk).

Notes: *Calculated by authors of this report. ${ }^{+}$Controlled study with matching.

Abbreviations: $\mathrm{RR}$, relative risk; $\mathrm{Cl}$, confidence interval; $\mathrm{RCT}$, randomized controlled trial; $\mathrm{NIV}$, noninvasive ventilation.

not statistically significant. Evidence on exacerbations not leading to hospitalization based on four RCTs ${ }^{17,19,21,24}$ and one controlled study ${ }^{29}$ showed no significant effect of NIV (Supplementary material). For QoL, there appeared to be a trend favoring NIV, but a consistent benefit could not be demonstrated; heterogeneity in outcomes measured and time points hampered analyses of this measure (Supplementary material). There was some evidence to suggest that NIV improved blood gases (based on mainly unadjusted results; Figures 4 and 5).

\section{NIV compared with usual care only: posthospital} population

No survival benefit was evident from three RCTs ${ }^{31-33}$ (pooled RR $0.89[0.53,1.49], I^{2}=25.1 \%$ ), though four nonrandomized controlled studies, ${ }^{34-37}$ which are potentially more prone to bias, favored NIV (pooled RR 0.45 [0.32, 0.65], $I^{2}=0 \%$; Figure 2). Findings for hospital admissions were inconsistent, with one $\mathrm{RCT}^{33}$ finding a statistically significant benefit of NIV, one ${ }^{31}$ marginally favoring NIV, and one ${ }^{32}$ marginally favoring usual care (without NIV) (Figure 3). QoL data were reported in only one posthospital $\mathrm{RCT},{ }^{32}$ and there were no differences between NIV and usual care. Limited data from three trials ${ }^{31-33}$ suggested a potential benefit from NIV in terms of reduction in $\mathrm{PaCO}_{2}$ (Figure 5).

\section{Study quality}

None of the RCTs assessed as having a high risk of bias contributed data to meta-analyses; yet some of the nonrandomized controlled studies in the meta-analyses 


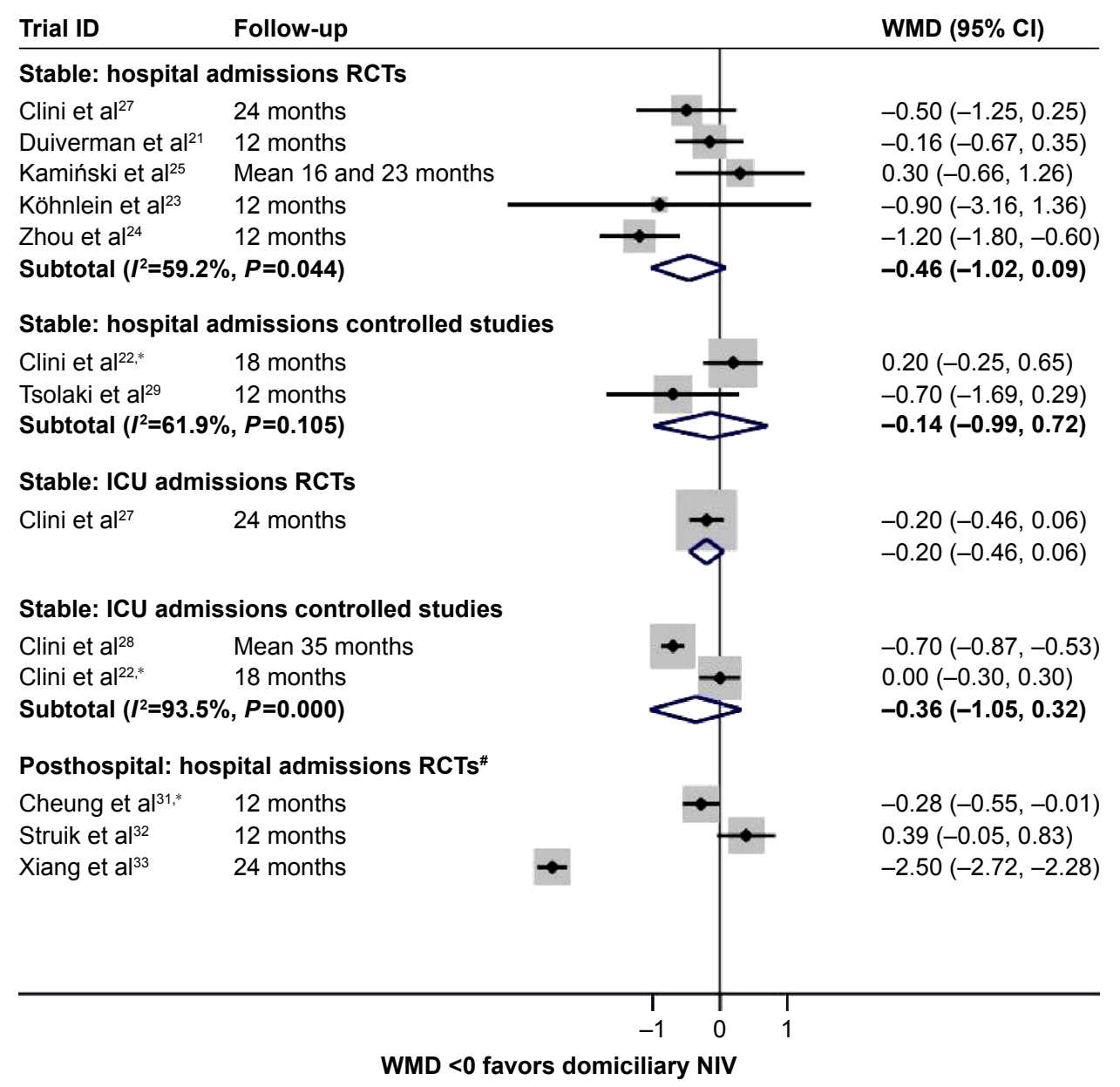

Figure 3 Hospital admissions per patient per year (weighted mean difference).

Notes: *Calculated by authors of this report. \#Individual mean differences $(95 \% \mathrm{Cl})$ presented for this outcome.

Abbreviations: $\mathrm{Cl}$, confidence interval; WMD, weighted mean difference; RCTs, randomized controlled trials; ICU, intensive care unit; NIV, noninvasive ventilation.

(for both populations) did. The small number of studies precluded assessment of the potential for publication bias (eg, using funnel plots) and sensitivity analyses around study quality.

\section{Subgroup analysis}

No further subgroup analysis (beyond study design and population) was possible, given the small number of trials and inconsistent reporting of relevant characteristics. However, many clinicians believe that the extent of hypercapnia or a change in hypercapnia status is related to the effect of NIV. In this context, it is worth noting that the study by Köhnlein et $\mathrm{al}^{23}$ had the highest hypercapnia threshold as an eligibility criterion $\left(\mathrm{PaCO}_{2} \geq 7 \mathrm{kPa}\right)$, and also showed a statistically significant survival benefit (and a nonsignificant trend toward fewer hospital admissions). Further, the study by Zhou et $\mathrm{al}^{24}$ which along with the Köhnlein et $\mathrm{al}^{23}$ study had the highest mean $\mathrm{PaCO}_{2}$, found a statistically significant benefit from NIV in hospital admissions. In order to explore the hypercapnia level further as a potential predictor of benefit from NIV, data on mean $\mathrm{PaCO}_{2}$ levels prior to initiation of NIV and change in mean $\mathrm{PaCO}_{2}$ levels due to NIV from each study (where reported) were plotted against mortality and hospitalization data in order to determine if baseline $\mathrm{PaCO}_{2}$ levels could predict response to NIV, and whether the effect of NIV on $\mathrm{PaCO}_{2}$ levels correlates with the effect on clinical outcomes (Figure 6A-D). These exploratory analyses suggested a trend toward a correlation between changes in hypercapnia status and hospital admissions (based on eight $\left.\mathrm{RCTs}^{21,23-25,27,31-33}\right)$. Such a potential correlation was not observed for mortality (based on ten RCTs ${ }^{19,21,23-27,31-33}$ ). Baseline hypercapnia status did not appear to predict response to NIV for mortality (based on ten RCTs ${ }^{19,21,23-27,31-33}$ ); the data were suggestive of a possible trend toward a correlation between baseline hypercapnia and hospital admissions (based on eight $\left.\mathrm{RCTs}^{21,23-25,27,31-33}\right)$. Formal subgroup analysis based on the level of hypercapnia was however not deemed to be appropriate as this would have meant dichotomizing trials 


\begin{tabular}{|c|c|c|c|c|}
\hline Study & $\begin{array}{l}\text { Baseline } \\
\text { difference } \\
\text { (NIV-control) }\end{array}$ & $\begin{array}{l}\text { Follow-up } \\
\text { period }\end{array}$ & & $\begin{array}{l}\text { Mean difference } \\
\text { (NIV-control, 95\% CI) }\end{array}$ \\
\hline \multicolumn{5}{|c|}{ Stable: adjusted for baseline } \\
\hline Duiverman et $\mathrm{al}^{20}$ & -0.51 & 3 months & $\rightarrow-$ & $0.25(-0.20,0.70)$ \\
\hline Duiverman et $\mathrm{al}^{21}$ & -0.61 & 24 months & $\longrightarrow$ & $0.80(0.05,1.55)$ \\
\hline \multicolumn{5}{|l|}{ Stable: change score } \\
\hline Garrod et al ${ }^{18}$ & -3.3 & 3 months & $\multimap$ & $0.49(0.03,0.95)$ \\
\hline Meecham-Jones et al ${ }^{41}$ & 0 & 3 months & $\rightarrow-$ & $0.79(0.39,1.19)$ \\
\hline Strumpf et $a^{53}$ & 0 & 3 months & $\rightarrow$ & $0.27(-0.46,1.00)$ \\
\hline \multicolumn{5}{|l|}{ Stable: final score } \\
\hline Gay et al ${ }^{51, *}$ & 1.14 & 3 months & & $1.36(-0.29,3.01)$ \\
\hline Bhatt et $\mathrm{al}^{17,^{*}}$ & -1.17 & 6 months & & $0.05(-1.17,1.27)$ \\
\hline Casanova et $\mathrm{al}^{19, *}$ & -0.24 & 6 months & - & $-0.13(-0.72,0.46)$ \\
\hline Duiverman et $\mathrm{al}^{21, *}$ & -0.61 & 6 months & $\rightarrow$ & $0.66(0.21,1.11)$ \\
\hline Zhou et $\mathrm{al}^{24, *}$ & 0.07 & 6 months & $\longrightarrow$ & $1.04(0.48,1.60)$ \\
\hline Clini et $\mathrm{al}^{27, *}$ & -0.03 & 12 months & & $0.35(-1.03,1.73)$ \\
\hline Duiverman et $\mathrm{al}^{21, *}$ & -0.61 & 12 months & 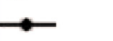 & $0.47(0.00,0.94)$ \\
\hline Zhou et $\mathrm{al}^{24, *}$ & 0.07 & 12 months & $\rightarrow-$ & $0.52(0.07,0.97)$ \\
\hline Clini et $\mathrm{al}^{27, *}$ & -0.3 & 24 months & & $-0.03(-1.41,1.35)$ \\
\hline \multicolumn{5}{|c|}{ Posthospital: change score } \\
\hline Struik et $\mathrm{al}^{32, \mathrm{a}}$ & 0.4 & 12 months & & $-0.60(-1.40,0.20)$ \\
\hline Struik et $a^{32, b}$ & NR & 12 months & - & $-0.30(-1.20,0.60)$ \\
\hline \multicolumn{5}{|l|}{ Posthospital: final score } \\
\hline Xiang et $a^{33, *}$ & 0.13 & 24 months & $\rightarrow$ & $1.06(0.75,1.37)$ \\
\hline
\end{tabular}

Figure $4 \mathrm{PaO}_{2}$ (mean difference).

Notes: *Calculated by authors of this report. a Measurement performed regardless of oxygen use. beasurements both on room air or both on oxygen at the same flow rate.

Abbreviations: $\mathrm{PaO}_{2}$, partial pressure of oxygen; $\mathrm{NIV}$, noninvasive ventilation; $\mathrm{Cl}$, confidence interval; $\mathrm{NR}$, not reported.

based on an arbitrary $\mathrm{CO}_{2}$ threshold. Adherence to NIV and effect of NIV settings could also not be analyzed.

\section{Different types of NIV}

With regard to the effectiveness of different NIV settings, three small crossover trials in stable populations were identified: two ${ }^{38,39}$ comparing higher vs lower pressure NIV and one $^{40}$ comparing different back-up rates. All were short term (6-8 weeks) and did not assess mortality or hospitalizations/ exacerbations. Treatment compliance was similar between arms in two studies, ${ }^{39,40}$ and higher in the high-pressure arm for the third, ${ }^{38}$ but drop-out rates were high in the pressure trials. ${ }^{38,39}$ The limited QoL data precluded drawing firm conclusions. The only statistically significant result ${ }^{38}$ was greater $\mathrm{PaCO}_{2}$ reduction with high-pressure NIV (Supplementary material).

\section{Discussion}

This is the first systematic review of domiciliary NIV to attempt to account for differing baseline risks of exacerbation by categorizing populations into stable and posthospital based on proximity to an in-patient stay for an exacerbation; it is also the most comprehensive review to date, including evidence from RCTs, nonrandomized controlled studies, and RCTs comparing different NIV settings, and without restriction to English language-only publications. Overall, the evidence from RCTs in a stable population could not demonstrate benefit for mortality from domiciliary NIV compared to usual care alone (seven RCTs ${ }^{19,21,23-27}$ and four controlled studies $^{22,28-30}$ ), although there was a trend toward fewer hospital admissions (five RCTs $\mathrm{s}^{21,23-25,27}$ and three controlled studies $^{22,28,29}$ ), and to a lesser extent, improved QoL (seven $\operatorname{RCTs}^{17,18,21,23,26,27,41}$ and one controlled study ${ }^{29}$ ), for the stable population. A survival benefit for the posthospital population could not be shown based on three RCTs, ${ }^{31-33}$ though there was some evidence of benefit based on four (potentially biased) nonrandomized controlled studies. ${ }^{34-37}$ Findings for hospital admissions (three RCTs ${ }^{31-33}$ ) were inconsistent. There was too little evidence to draw any conclusions on the potential benefits of high-pressure NIV settings. 


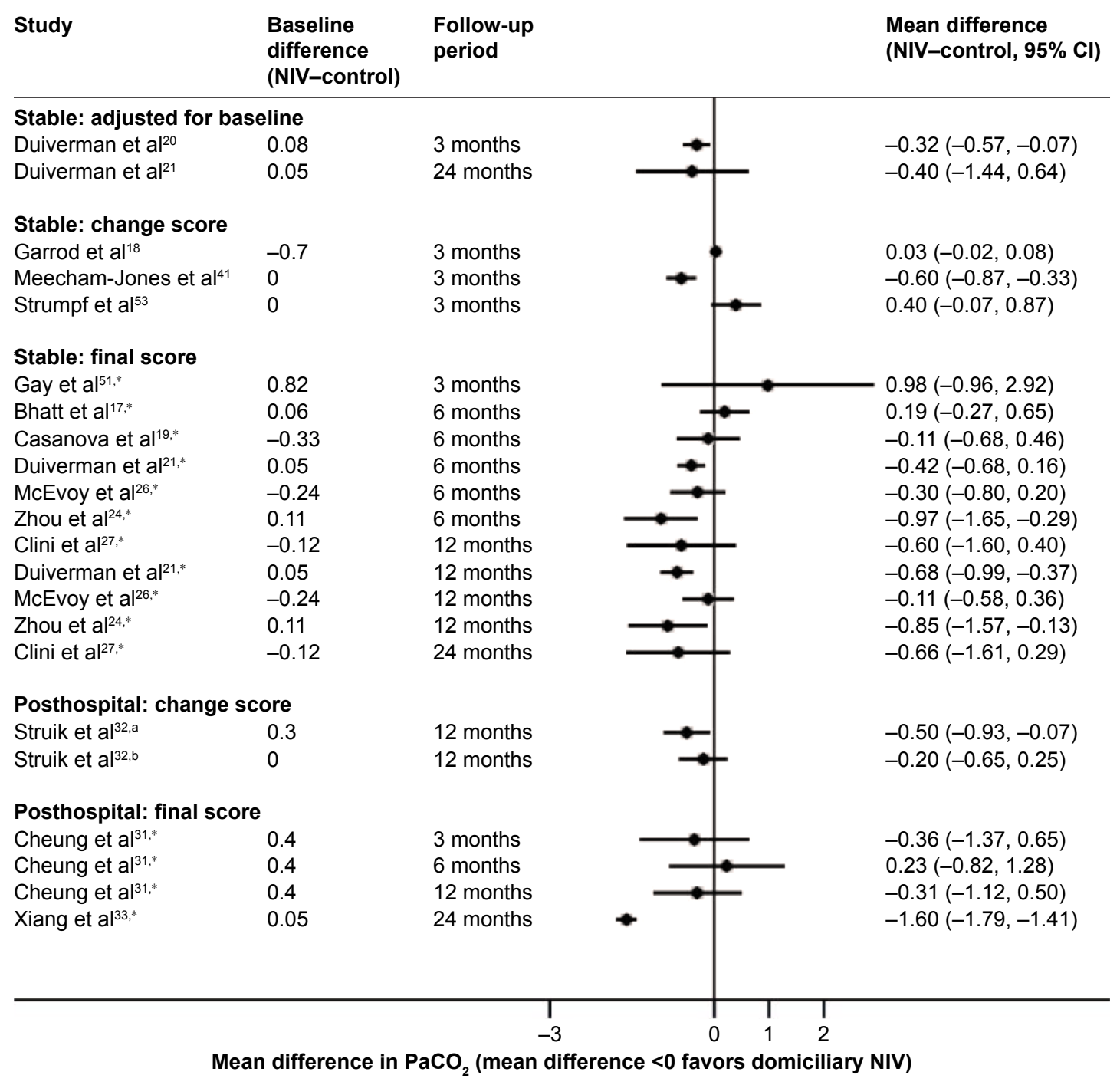

Figure $5 \mathrm{PaCO}_{2}$ (mean difference).

Notes: *Calculated by authors of this report. aMeasurement performed regardless of oxygen use. bMeasurements both on room air or both on oxygen at the same flow rate. Abbreviations: $\mathrm{PaCO}_{2}$, partial pressure of carbon dioxide; $\mathrm{NIV}$, noninvasive ventilation; $\mathrm{Cl}$, confidence interval.

\section{Exacerbation risk and domiciliary NIV}

It was hoped that subgroup analyses based on the frequency of exacerbations prior to NIV treatment would be possible, as frequent exacerbators (patients with two or more exacerbations/year) are a clinically relevant subgroup, ${ }^{42}$ with a generally stable exacerbation frequency on other existing therapies. ${ }^{43}$ However, this was hampered by lack of reporting of this parameter.

There is evidence, however, to support the use of recent hospitalization as a proxy for a higher risk of recurring exacerbation. Prior hospital admission is recognized to be the biggest driver for a further exacerbation requiring admission, ${ }^{12}$ and NIV use in hospital has also been recognized as a predictor of overall exacerbation rate. ${ }^{44}$ Furthermore, recurrent type 2 respiratory failure, that is, respiratory failure with carbon dioxide retention, occurs in over $30 \%$, and readmission at
1 year in $60 \%$, of those who require NIV acutely in hospital. ${ }^{45}$ Consequently, stratification based on NIV started at recent hospitalization was thought to be a justifiable surrogate marker of exacerbation risk. In reality, there is likely to be much more of a continuum of risk, and it is further unknown what proportion of the posthospital populations considered in the individual studies are COPD patients at the more severe end of the disease spectrum.

\section{Which patients may benefit from domiciliary NIV?}

The results of the review show that division of data based on potential exacerbation risk did not indicate a difference between populations in terms of mortality or hospitalizations; in fact, there was no clear evidence for benefit for either population, though there was a nonsignificant trend toward 
A

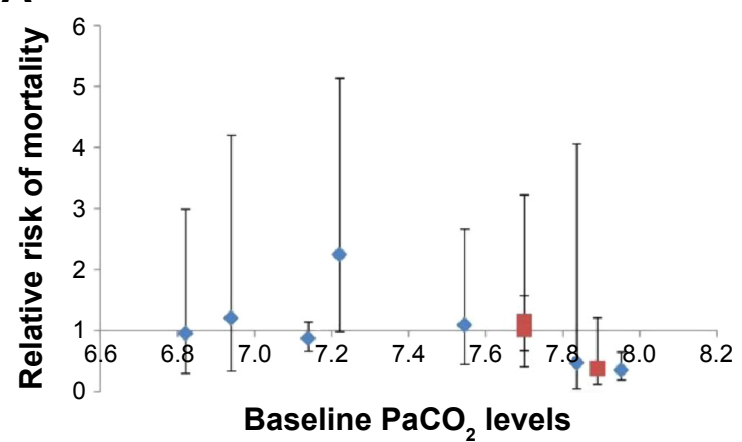

C

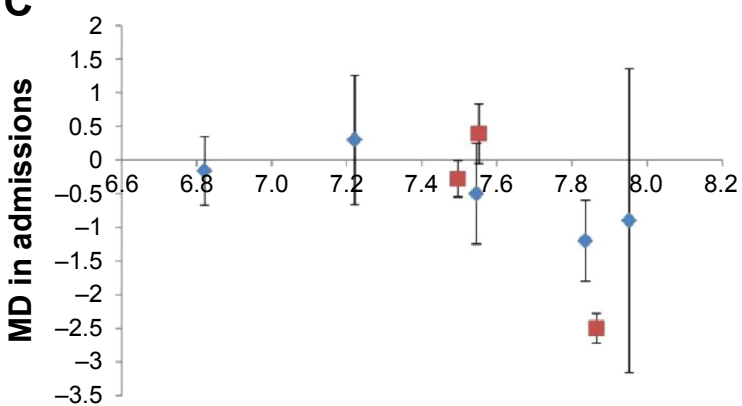

Baseline $\mathrm{PaCO}_{2}$ levels
B

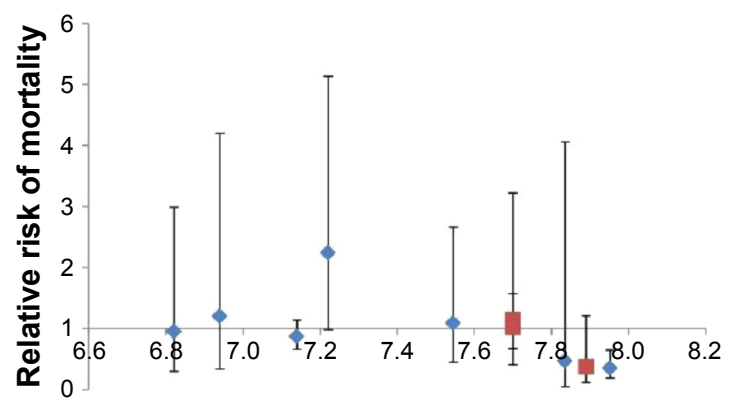

Baseline $\mathrm{PaCO}_{2}$ levels

D

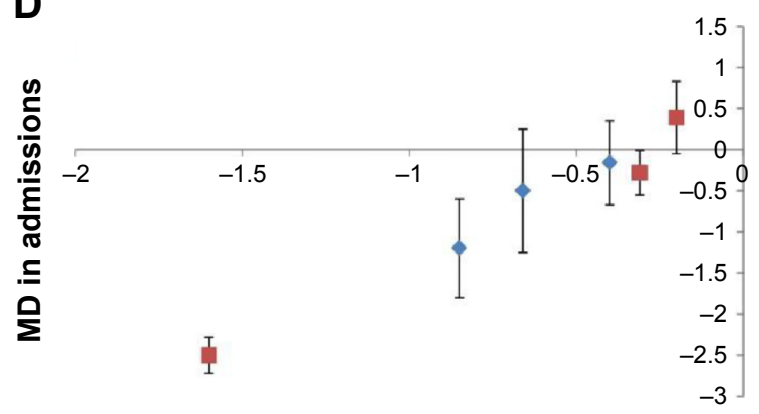

Change in $\mathrm{PaCO}_{2}$ levels

- Stable population Posthospital population

Figure 6 Hypercapnia and clinical outcomes.

Notes: (A) Mortality (RR) and baseline $\mathrm{PaCO}_{2}$. (B) Mortality (RR) and change in $\mathrm{PaCO}_{2}$. (C) Hospital admissions (MD) and baseline PaCO . (D) Hospital admissions (MD) and change in $\mathrm{PaCO}_{2}$.

Abbreviations: $\mathrm{RR}$, relative risk; $\mathrm{PaCO}_{2}$, partial pressure of carbon dioxide; $\mathrm{MD}$, mean difference.

a benefit with NIV in the stable population, for hospital admissions. The apparent similarity in hospitalization effect in our chosen subgroups is perhaps surprising, given that those previously admitted are at higher risk of subsequent readmission. It is possible that the division used failed to capture other important differences within and between populations; for example, the pretreatment exacerbation rates were unknown. There was evidence of some heterogeneity between both stable and posthospital studies, with some studies showing a significant benefit from NIV; one $\mathrm{RCT}^{23}$ in a stable population showed a statistically significant benefit from NIV for mortality (Figure 2), and one RCT for stable ${ }^{24}$ and two for posthospital populations ${ }^{31,33}$ showed significant benefit for hospital admissions (Figure 3). Two of these $\mathrm{RCTs}^{23,33}$ used a higher hypercapnia threshold for patient inclusion $\left(\mathrm{PaCO}_{2}>7 \mathrm{kPa}\right)$; one $\mathrm{RCT}^{25}$ had a lower inclusion criterion $\left(\mathrm{PaCO}_{2}>6 \mathrm{kPa}\right)$, though means were suggestive of higher levels. There was no detail on the inclusion threshold for the third RCT. ${ }^{24}$

Elements such as blood gases, prior admissions, and social support have been identified as drivers to clinical decision making regarding domiciliary NIV in COPD, ${ }^{46}$ all of which may impact NIV efficacy. The nonrandomized posthospital studies $^{22,28-30}$ assessing mortality (Figure 2) suggest a beneficial effect from NIV (significant pooled RR), however, it is possible that patient selection for NIV biased findings toward a positive response to NIV.

Most populations included in studies were hypercapnic (Table 2), although the threshold used to define this varied. Post hoc analyses undertaken across both stable and posthospital populations suggested a trend toward a positive correlation between changes in hypercapnia and hospital admissions (but not for mortality or correlation using pretreatment $\mathrm{PaCO}_{2}$ level). As these are exploratory analyses, the results should be interpreted cautiously; the analysis used aggregate - study-level - data for baseline hypercapnia, change in hypercapnia, and clinical outcomes, and a patient-level association cannot be inferred even if there is clear biological plausibility. Further caveats relate to the fact that not all trials contributed data to these analyses and that $\mathrm{PaCO}_{2}$ change scores were mostly not adjusted for baseline differences. Nevertheless, it does suggest that there should be further investigation of the association between hypercapnia and clinical outcomes, particularly with regard 
to the ability of the NIV to reduce $\mathrm{PaCO}_{2}$ levels. Patients hypercapnic at discharge may normalize their $\mathrm{PaCO}_{2}$ levels over time, although those who remain hypercapnic have higher mortality. ${ }^{47}$ Thus, if hypercapnia (or change in hypercapnia) were a driver of NIV response and were used to select patients for treatment after an exacerbation, subsequent reassessment may be needed to determine likelihood of ongoing benefit.

The current recommendation in the UK suggests that domiciliary NIV is considered on health economic grounds if a patient has had three hospital admissions with acute hypercapnic respiratory failure. ${ }^{48}$ There may be other, as yet unconfirmed, patient characteristics which influence its effectiveness. Uncertainty also remains regarding the length of time NIV may provide benefit for; there are at least two $\mathrm{RCTs}^{49,50}$ looking at the effect of discontinuing NIV, but this question was beyond the scope of this systematic review.

\section{Strengths and limitations}

A number of RCTs of reasonably good methodological quality were available, particularly for the stable population, and a comprehensive search strategy meant that this systematic review identified more relevant studies than previous ones, even after taking into account different search periods. No language restrictions meant that $19 \%$ of the included studies were non-English, a substantial proportion of the overall evidence base omitted by prior reviews..$^{8-11}$ This is also the first systematic review to examine patient-related outcomes and incorporate data from nonrandomized studies. Furthermore, by calculating summary measures from raw data or converting data, the number of results that could be presented in forest plots was maximized. In contrast to some previous systematic reviews, secondary outcome data (lung function, blood gases, and 6-minute walk distance) were not pooled due to a lack of results adjusted for baseline differences. This means that our analyses are likely to be more robust.

There were several limitations in the available data, largely due to inconsistency of reporting (particularly for hospital admissions) or measurement tools (especially for QoL). This meant that not all available evidence could contribute to the pooled estimates. Furthermore, admissions data may be skewed; thus, the mean (SD) may not be an appropriate metric to use, though it was frequently reported. For primary outcomes, there was a lack of data explicitly linking the number of exacerbations to subsequent hospitalizations and survival for individual patients. This latter point has potential implications for double-counting data as these outcomes are not independent of each other.
Ventilator settings may influence effectiveness, and settings have changed over time, such that earlier settings may be considered ineffective today. The small crossover trials ${ }^{38-40}$ in this analysis did not allow any conclusions to be drawn, and subgroup analysis based on the larger/parallel trials was not possible due to inconsistent reporting: studies variously reported mean, median, or target settings, based on pressure, blood gas, or volume targets, with some stating only that levels were adjusted to patient comfort/tolerance. Reporting times also varied (eg, at start of study or at discharge).

\section{Recommendations for future research pertaining to domiciliary NIV in COPD}

Variable quality of data reporting, lack of exacerbation data, potential bias, and heterogeneity of reported outcomes were striking features of the included studies. These features are not uncommonly encountered when conducting systematic reviews. While trials of medications are often required to report certain outcomes as part of the licensing process, medical device studies, such as those included in our review, have not always had to meet such standards despite also being subject to regulatory processes. More detailed reporting of exacerbations in particular would be valuable in this high-risk population. It has been suggested that new RCTs could include a sham NIV arm in order to minimize potential bias, as well as high- and low-pressure NIV arm to enable further exploration of the relationship between pressure and effectiveness; many of the earlier studies included used pressures which experts would now consider equivalent to a sham treatment. ${ }^{19}$ However, sham NIV could lead to an overestimate of the potential benefit of NIV, due to its potential disbenefits on QoL; therefore, two control arms (with and without sham NIV) are more likely to be appropriate. Qualitative work in NIV users and prescribers not surprisingly suggests that a focus on patient-centered measures (eg, QoL, daily activity) is needed, alongside research to delineate those in whom the treatment is most effective. ${ }^{46}$ Which instruments best capture QoL in this patient group and whether instruments are convertible is debatable.

There is at least one ongoing trial (the UK HOT-HMV trial, NCT00990132), which includes a population with an underlying risk of recurrent events similar to the posthospital population described in this study. Findings from this trial will be important, but additional evidence from individual patient data analyses of pooled studies may be required to determine whether specific patient characteristics or equipment settings predict benefit from NIV, and to establish optimum time points for starting (and potentially 
discontinuing) NIV. A previous review ${ }^{8,9}$ attempted such analyses, but based on a smaller group of studies, and without considering hospitalizations or survival.

\section{Conclusion}

The effectiveness of domiciliary NIV remains uncertain; however, some patients appear to benefit. Further research is required to identify these patients and to explore the relevance of hypercapnic status or changes in hypercapnia due to NIV in influencing clinical outcomes for patients on long-term NIV; optimum time points for starting NIV and equipment settings also need to be established.

\section{Acknowledgments}

The authors thank the following: Simon Stevens for his invaluable administrative support and excellent organizational skills; all members of the patient group for supporting and contributing to this project: Maireade Bird, Michael Darby, Don Etheridge, Chris Huckle, Jan Turner, and Anne Yeomans; Chris Cates, Peymane Adab, Brendan Cooper, and Rob Stockley for contributions to wider team meetings; and all the people who kindly gave their time to help translate articles. This article summarizes independent research funded by the National Institute for Health Research (NIHR) under its HTA Programme (Ref 11/27/01). The views expressed are those of the authors and not necessarily those of the NHS, the NIHR, or the Department of Health.

\section{Author contributions}

JD was the lead systematic reviewer, wrote and edited sections of the paper, and undertook study selection, data extraction and analysis, and quality assessment. DM was co-principle investigator and methodological lead, led all aspects of the project, contributed to all aspects of the project, undertook study selection, and wrote and edited sections of the paper. CD and RM advised on clinical aspects of the project, and undertook study selection. MP advised on statistical aspects, analyzed data, and edited statistical methodological sections of the paper. SB devised the search strategies and ran the searches in electronic databases. XW translated Chinese papers, and undertook data extraction and data checking. RJ undertook study selection and contributed to methodological aspects of the project. AT was co-principle investigator and clinical lead, oversaw all clinical aspects of the project, undertook study selection, and wrote and commented on sections of the paper. All authors contributed toward data analysis, drafting and critically revising the paper and agree to be accountable for all aspects of the work.

\section{Disclosure}

AT's clinic has been loaned sleep monitors by ResMed Inc. which also produces NIV equipment. RM has received nonfinancial support from ResMed Inc. and Breas Medical in the form of training sessions for the NIV equipment supplied to his NIV multidisciplinary team. DM and JD acted as peer reviewers for the Cochrane systematic review by Struik et al ${ }^{8}$ which is included in this report. RJ was awarded a grant in respect of an NIHR postdoctoral fellowship during the conduct of the study. The fellowship relates to a different COPD project. The authors report no other conflicts of interest in this work.

\section{References}

1. Vestbo J, Hurd SS, Agusti AG, et al. Global strategy for the diagnosis, management, and prevention of chronic obstructive pulmonary disease: GOLD executive summary. Am J Respir Crit Care Med. 2013;187(4): 347-365.

2. Seemungal T, Donaldson G, Paul E, Bestall J, Jeffries D, Wedzicha J. Effect of exacerbation on quality of life in patients with chronic obstructive pulmonary disease. Am J Respir Crit Care Med. 1998;157(5 Pt 1): $1418-1422$.

3. Britton M. The burden of COPD in the U.K.: results from the Confronting COPD survey. Respir Med. 2003;97 Suppl C:S71-S79.

4. Roberts CM, Lowe D, Bucknall CE, Ryland I, Kelly Y, Pearson MG. Clinical audit indicators of outcome following admission to hospital with acute exacerbation of chronic obstructive pulmonary disease. Thorax. 2002;57(2):137-141.

5. Connors AF Jr, Dawson NV, Thomas C, et al. Outcomes following acute exacerbation of severe chronic obstructive lung disease. The SUPPORT investigators (Study to Understand Prognoses and Preferences for Outcomes and Risks of Treatments). Am J Respir Crit Care Med. 1996; 154(4):959-967.

6. National Institute for Clinical Excellence (NICE). Chronic obstructive pulmonary disease: national clinical guideline for management of chronic obstructive pulmonary disease in adults in primary and secondary care. Thorax. 2004;59(Suppl 1):1-232.

7. Ram FS, Picot J, Lightowler J, Wedzicha JA. Non-invasive positive pressure ventilation for treatment of respiratory failure due to exacerbations of chronic obstructive pulmonary disease. Cochrane Database Syst Rev. 2004;(1):CD004104.

8. Struik FM, Lacasse Y, Goldstein RS, Kerstjens HA, Wijkstra PJ. Nocturnal noninvasive positive pressure ventilation in stable COPD: a systematic review and individual patient data meta-analysis. Respir Med. 2014;108(2):329-337.

9. Struik FM, Lacasse Y, Goldstein R, Kerstjens HM, Wijkstra PJ. Nocturnal non-invasive positive pressure ventilation for stable chronic obstructive pulmonary disease. Cochrane Database Syst Rev. 2013;6: CD002878.

10. Shi JX, Xu J, Sun WK, Su X, Zhang Y, Shi Y. Effect of noninvasive, positive pressure ventilation on patients with severe, stable chronic obstructive pulmonary disease: a meta-analysis. Chin Med J (Engl). 2013;126(1):140-146.

11. Chandra K, Blackhouse G, McCurdy B, et al. Cost-effectiveness of interventions for chronic obstructive pulmonary disease (COPD) using an Ontario policy model. Ont Health Technol Assess Ser. 2012; 12(12):1-61.

12. Mullerova H, Maselli DJ, Locantore N, et al. Hospitalized exacerbations of COPD: risk factors and outcomes in the ECLIPSE cohort. Chest. 2015;147(4):999-1007. 
13. Dave C, Turner A, Dretzke J, et al. Protocol for a systematic review and economic evaluation of the clinical and cost-effectiveness of non-hospital-based non-invasive ventilation (NIV) in patients with stable end-stage COPD with hypercapnic respiratory failure. Syst Rev. 2014;3:32.

14. Janine D, David M, Alice T, et al. Systematic review and economic evaluation of the clinical and cost-effectiveness of community based non-invasive ventilation (NIV) in patients with stable end stage COPD with hypercapnic respiratory failure. PROSPERO 2012:CRD42012003286. Available from: http://www.crd.york.ac.uk/ PROSPERO/display_record.asp?ID=CRD42012003286.

15. Higgins JPT, Deeks JJ, Altman D, Gobot CSMG. Special topics in statistics. Available from: http://www.cochrane-handbook.org/. Accessed October 23, 2012.

16. Ottawa Hospital Research Institute. PRISMA. Transparent reporting of systematic reviews and meta-analyses. Available from: http://www. prisma-statement.org/. Accessed October 17, 2012.

17. Bhatt SP, Peterson MW, Wilson JS, Durairaj L. Noninvasive positive pressure ventilation in subjects with stable COPD: a randomized trial. Int J Chron Obstruct Pulmon Dis. 2013;8:581-589.

18. Garrod R, Mikelsons C, Paul EA, Wedzicha JA. Randomized controlled trial of domiciliary noninvasive positive pressure ventilation and physical training in severe chronic obstructive pulmonary disease. Am J Respir Crit Care Med. 2000;162(4 Pt 1):1335-1341.

19. Casanova C, Celli BR, Tost L, et al. Long-term controlled trial of nocturnal nasal positive pressure ventilation in patients with severe COPD. Chest. 2000;118(6):1582-1590

20. Duiverman ML, Wempe JB, Bladder G, et al. Nocturnal non-invasive ventilation in addition to rehabilitation in hypercapnic patients with COPD. Thorax. 2008;63(12):1052-1057.

21. Duiverman ML, Wempe JB, Bladder G, et al. Two-year home-based nocturnal noninvasive ventilation added to rehabilitation in chronic obstructive pulmonary disease patients: a randomized controlled trial. Respir Res. 2011;12(1):112

22. Clini E, Vitacca M, Foglio K, Simoni P, Ambrosino N. Long-term home care programmes may reduce hospital admissions in COPD with chronic hypercapnia. Eur Respir J. 1996;9(8):1605-1610.

23. Köhnlein T, Windisch W, Köhler D, et al. Non-invasive positive pressure ventilation for the treatment of severe stable chronic obstructive pulmonary disease: a prospective, multicentre, randomised, controlled clinical trial. Lancet Respir Med. 2014;2(9):698-705.

24. Zhou X, Yang J, Shen C. Effect of non-invasive positive pressure ventilation and long-term oxygen therapy in patients with stable COPD. Clin Med J China. 2008;15(4):486-488

25. Kamiński D, Sliwiński P, Bieleń P, Zieliński J. [Noninvasive positive pressure ventilation in COPD patients with hypercapnic respiratory failure]. Nieinwazyjne wspomaganie wentylacji dodatnim ciśnieniem u chorych na POChP w okresie hiperkapnicznej niewydolności oddychania. Pneumonol Alergol Pol. 1999;67:45-52. Polish.

26. McEvoy RD, Pierce RJ, Hillman D, et al. Nocturnal non-invasive nasal ventilation in stable hypercapnic COPD: a randomised controlled trial. Thorax. 2009;64(7):561-566.

27. Clini E, Sturani C, Rossi A, et al. The Italian multicentre study on noninvasive ventilation in chronic obstructive pulmonary disease patients. Eur Respir J. 2002;20(3):529-538.

28. Clini E, Sturani C, Porta R, et al. Outcome of COPD patients performing nocturnal non-invasive mechanical ventilation. Respir Med. 1998;92(10): 1215-1222.

29. Tsolaki V, Pastaka C, Karetsi E, et al. One-year non-invasive ventilation in chronic hypercapnic COPD: effect on quality of life. Respir Med. 2008; 102(6):904-911.

30. Paone G, Conti V, Biondi-Zoccai G, et al. Long-term home noninvasive mechanical ventilation increases systemic inflammatory response in chronic obstructive pulmonary disease: a prospective observational study. Mediators Inflamm. 2014;2014:503145.
31. Cheung AP, Chan VL, Liong JT, et al. A pilot trial of non-invasive home ventilation after acidotic respiratory failure in chronic obstructive pulmonary disease. Int J Tuberc Lung Dis. 2010;14(5):642-649.

32. Struik FM, Sprooten RT, Kerstjens HA, et al. Nocturnal non-invasive ventilation in COPD patients with prolonged hypercapnia after ventilatory support for acute respiratory failure: a randomised, controlled, parallel-group study. Thorax. 2014;69(9):826-834.

33. Xiang PC, Zhang X, Yang JN, et al. [The efficacy and safety of long term home noninvasive positive pressure ventilation in patients with stable severe chronic obstructive pulmonary disease]. Zhonghua Jie He He Hu Xi Za Zhi. 2007;30(10):746-750. Chinese.

34. Lu P, Wu XM, Li ZG, Yang CC. [Clinical observation of home noninvasive positive pressure ventilation in hypercapnic patient with stable severe chronic obstructive pulmonary disease]. Zhonghua Yi Xue Za Zhi. 2012;92(6):401-404. Chinese.

35. Heinemann F, Budweiser S, Jorres RA, et al. The role of non-invasive home mechanical ventilation in patients with chronic obstructive pulmonary disease requiring prolonged weaning. Respirology. 2011;16(8): 1273-1280.

36. Budweiser S, Hitzl AP, Jorres RA, et al. Impact of noninvasive home ventilation on long-term survival in chronic hypercapnic COPD: a prospective observational study. Int J Clin Pract. 2007;61(9):1516-1522.

37. Milane J, Jonquet O. Intermittent positive pressure breathing in the treatment of respiratory insufficiency by chronic lung disease. Agressologie. 1985;26(8):651-655.

38. Dreher M, Storre JH, Schmoor C, Windisch W. High-intensity versus low-intensity non-invasive ventilation in patients with stable hypercapnic COPD: a randomised crossover trial. Thorax. 2010;65(4):303-308.

39. Oscroft NS, Ali M, Gulati A, et al. A randomised crossover trial comparing volume assured and pressure preset noninvasive ventilation in stable hypercapnic COPD. COPD. 2010;7(6):398-403.

40. Murphy PB, Brignall K, Moxham J, Polkey MI, Davidson AC, Hart N. High pressure versus high intensity noninvasive ventilation in stable hypercapnic chronic obstructive pulmonary disease: a randomized crossover trial. Int J Chron Obstruct Pulmon Dis. 2012;7: 811-818.

41. Meecham-Jones DJ, Paul EA, Jones PW, Wedzicha JA. Nasal pressure support ventilation plus oxygen compared with oxygen therapy alone in hypercapnic COPD. Am J Respir Crit Care Med. 1995;152(2): 538-544.

42. Turner AM, Tamasi L, Schleich F, et al. Clinically relevant subgroups in COPD and asthma. Eur Respir Rev. 2015;24(136):283-298.

43. Hurst JR, Vestbo J, Anzueto A, et al. Susceptibility to exacerbation in chronic obstructive pulmonary disease. N Engl J Med. 2010;363(12): $1128-1138$.

44. Yang H, Xiang P, Zhang E, et al. Predictors of exacerbation frequency in chronic obstructive pulmonary disease. Eur J Med Res. 2014;19(1):18.

45. Chung LP, Winship P, Phung S, Lake F, Waterer G. Five-year outcome in COPD patients after their first episode of acute exacerbation treated with non-invasive ventilation. Respirology. 2010;15(7):1084-1091.

46. Gale N, Jawad M, Dave C, Turner AM. Adapting to domiciliary non-invasive ventilation in chronic obstructive pulmonary disease: a qualitative interview study. Palliat Med. 2015;29(3):268-277.

47. Costello R, Deegan P, Fitzpatrick M, McNicholas WT. Reversible hypercapnia in chronic obstructive pulmonary disease: a distinct pattern of respiratory failure with a favorable prognosis. Am J Med. 1997; 102(3):239-244

48. Tuggey JM, Plant PK, Elliott MW. Domiciliary non-invasive ventilation for recurrent acidotic exacerbations of COPD: an economic analysis. Thorax. 2003;58(10):867-871.

49. Funk GC, Breyer MK, Burghuber OC, et al. Long-term non-invasive ventilation in COPD after acute-on-chronic respiratory failure. Respir Med. 2011;105(3):427-434.

50. Oscroft NS, Quinnell TG, Shneerson JM, Smith IE. The effects of withdrawing long-term nocturnal non-invasive ventilation in COPD patients. COPD. 2010;7(2):111-116. 
51. Gay PC, Hubmayr RD, Stroetz RW. Efficacy of nocturnal nasal ventilation in stable, severe chronic obstructive pulmonary disease during a 3-month controlled trial. Mayo Clin Proc. 1996;71(6):533-542.

52. Sin DD, Wong E, Mayers I, et al. Effects of nocturnal noninvasive mechanical ventilation on heart rate variability of patients with advanced COPD. Chest. 2007;131(1):156-163.

53. Strumpf DA, Millman RP, Carlisle CC, et al. Nocturnal positive-pressure ventilation via nasal mask in patients with severe chronic obstructive pulmonary disease. Am Rev Respir Dis. 1991;144(6):1234-1239.

54. De Backer L, Vos W, Dieriks B, et al. The effects of long-term noninvasive ventilation in hypercapnic COPD patients: a randomized controlled pilot study. Int J Chron Obstruct Pulmon Dis. 2011;6:615-624.
55. Murphy PB, Moxham J, Polkey MI, Hart N. UK HOT-HMV trial: acceptability and tolerability of high pressure domiciliary non-invasive ventilation (NIV) in COPD. Thorax. 2011;66:A55.

56. Laier-Groeneveld G, Criee CP. [Long-term effects and life expectancy after six years intermittent self ventilation]. Langzeiteffekte und Lebenserwartung nach sechs Jahren unter intermittierender Selbstbeatmung. Med Klin (Munich). 1995;90(1 Suppl):62-63. German.

57. Pahnke J, Bullemer F, Heindl S, Karg O. [Patient-related rejection of nasal IPPV therapy. Patients, reasons, follow-up]. Patientenbedingte Ablehnung der nasalen IPPV-Therapie. Patienten, Gründe, Verlauf. Med Klin (Munich). 1997;92 Suppl 1:73-74. German.

\section{Publish your work in this journal}

The International Journal of COPD is an international, peer-reviewed journal of therapeutics and pharmacology focusing on concise rapid reporting of clinical studies and reviews in COPD. Special focus is given to the pathophysiological processes underlying the disease, intervention programs, patient focused education, and self management protocols.

\section{Dovepress}

This journal is indexed on PubMed Central, MedLine and CAS. The manuscript management system is completely online and includes a very quick and fair peer-review system, which is all easy to use. Visit $\mathrm{http} / / / \mathrm{www}$.dovepress.com/testimonials.php to read real quotes from published authors. 